OPEN ACCESS

Edited by:

Zexian Liu,

Sun Yat-sen University Cancer Center

(SYSUCC), China

Reviewed by:

Zi-Xian Wang

Sun Yat-sen University Cancer Center

(SYSUCC), China

Zhen Yu,

Shanghai First People's

Hospital, China

${ }^{*}$ Correspondence:

Jie-Hyun Kim

otilia94@yuhs.ac

Specialty section:

This article was submitted to

Gastrointestinal Cancers,

a section of the journal

Frontiers in Oncology

Received: 31 July 2019 Accepted: 29 October 2019

Published: 14 November 2019

Citation:

Kim YM, Kim J-H, Baik SJ, Chun J,

Youn YH and Park H (2019)

Sarcopenia and Sarcopenic Obesity

as Novel Risk Factors for Gastric

Carcinogenesis: A Health Checkup

Cohort Study. Front. Oncol. 9:1249.

doi: 10.3389/fonc.2019.01249

\section{Sarcopenia and Sarcopenic Obesity as Novel Risk Factors for Gastric Carcinogenesis: A Health Checkup Cohort Study}

\author{
Young Min Kim ${ }^{1}$, Jie-Hyun Kim ${ }^{1 *}$, Su Jung Baik ${ }^{2}$, Jaeyoung Chun ${ }^{1}$, Young Hoon Youn ${ }^{1}$ \\ and Hyojin Park ${ }^{1}$ \\ ${ }^{1}$ Department of Internal Medicine, Gangnam Severance Hospital, Yonsei University College of Medicine, Seoul, South Korea, \\ ${ }^{2}$ Department of Healthcare Research Team, Health Promotion Center, Gangnam Severance Hospital, Yonsei University \\ College of Medicine, Seoul, South Korea
}

Background: Insulin resistance, the primary mechanism of metabolic syndrome, promotes gastric carcinogenesis. Metabolic syndrome is associated with sarcopenia. We aimed to investigate the association between sarcopenia and gastric carcinogenesis, including precancerous conditions such as atrophic gastritis (AG), intestinal metaplasia (IM), and dysplasia.

Methods: The study included adult patients who underwent gastroduodenoscopy at a checkup center. AG and IM were evaluated using endoscopy. Based on muscle mass, sarcopenia was defined as a skeletal muscle index $<1$ standard deviation below the sex-specific mean for healthy adults aged 20-39 years (cutoff point: 29.3\% for males and $26.7 \%$ for females). Obesity was defined as a body mass index (BMI) $\geq 25 \mathrm{~kg} / \mathrm{m}^{2}$ according to the Asia-Pacific criteria. Sarcopenic obesity was defined as a combination of sarcopenia and obesity. The association between gastric carcinogenesis and sarcopenia was evaluated.

Results: Among 8,356 enrolled participants, 0.14 and 42.5\% were diagnosed with gastric cancer and precancerous conditions, respectively. Approximately $41.7 \%$ of gastric cancer patients and $16.9 \%$ of patients with precancerous conditions were diagnosed with sarcopenia. Both sarcopenic obesity (odds ratio $[\mathrm{OR}]=4.139, P=$ $0.016)$ and diabetes mellitus (DM) $(O R=5.152, P=0.005)$ were significantly associated with gastric cancer. Sarcopenia, DM, hypertension, dyslipidemia, Helicobacter pylori infection, smoking, and alcohol consumption were significantly associated with precancerous conditions.

Conclusions: Sarcopenia and sarcopenic obesity were associated with gastric carcinogenesis and may be novel risk factors for gastric carcinogenesis.

\footnotetext{
Keywords: gastric carcinogenesis, sarcopenia, sarcopenic obesity, metabolic syndrome, risk factor
} 


\section{INTRODUCTION}

Gastric cancer is one of the commonest malignancies, especially in East Asian countries, such as Korea and Japan (1). Although people aged $\geq 40$ years in Korea undergo biannual endoscopy as part of the National Cancer Screening program, Korea remains one of the countries with the highest incidence of gastric cancer in the world (2). For this reason, it is important to not only detect precancerous conditions or early gastric cancer through screening endoscopy but also control modifiable risk factors. Gastric cancer is a multistep and multifactorial disease. Precancerous conditions, including atrophic gastritis (AG), intestinal metaplasia (IM), and dysplasia, progress to gastric cancer because of multiple influencing factors $(3,4)$. To date, several risk factors such as Helicobacter pylori infection, diabetes mellitus (DM), obesity, smoking, alcohol consumption, and diet, including the consumption of salty or smoked foods, are known to be associated with gastric carcinogenesis $(5,6)$. Among these factors, DM and obesity are components of metabolic syndrome. Insulin resistance, the primary mechanism of metabolic syndrome, promotes the carcinogenesis of various malignancies, including gastric cancer (7).

Sarcopenia is defined as the progressive loss of muscle mass and function as a result of the aging process. It has been recognized as a major health problem because of its association with the risk of adverse outcomes, such as physical disability, poor quality of life, and death (8). With the aging of population, the prevalence of sarcopenia has been increasing, although it can vary according to the definition, method used to measure muscle mass, age, race, and sex $(9,10)$. When the BIA method was used, the prevalence in the non-Asian population was higher than that in the Asian population for men (19 vs. $10 \%$ ), and the prevalence in the non-Asian population was higher than that in the Asian population for women (20 vs. $11 \%)$. When dual-energy X-ray absorptiometry (DXA) was used, the prevalence in the Asian population was higher than that in the non-Asian population for men (9 vs. 6\%), and the prevalence in the non-Asian was higher than that in the Asian population for women (10 vs. $6 \%$ ). Previous studies reported that sarcopenia is associated with metabolic syndrome. As skeletal muscle is the primary tissue responsible for insulin-dependent glucose uptake, sarcopenia is associated with systemic insulin resistance, which progressively induces metabolic syndrome (11, 12). Recently, a "new concept," sarcopenic obesity, which refers to the coexistence of sarcopenia and obesity and which are both associated with metabolic syndrome, has a greater effect on metabolic disease, morbidity, and mortality than sarcopenia and obesity individually (13).

Because both gastric carcinogenesis and sarcopenia are associated with metabolic syndrome, we hypothesized that there is an association between gastric carcinogenesis and sarcopenia. To the best of our knowledge, only a limited number of studies have demonstrated this relationship. Hence, this study aimed to investigate risk factors for gastric carcinogenesis with a focus on sarcopenia and sarcopenic obesity among patients who underwent routine health checkups.

\section{MATERIALS AND METHODS}

\section{Study Design and Population}

This single-center study was conducted at Gangnam Severance Hospital, Seoul, Korea from August 2017 to August 2018. Starting in August 2017, our checkup center could measure skeletal muscle index (SMI). Data were retrospectively collected from electronic medical records of patients who visited our center for a routine health checkup. Overall, 9,332 Korean patients who underwent upper endoscopy at our checkup center were considered for this study. We excluded 976 patients with a history of gastric cancer or any type of cancer $(n=869)$; a history of gastric surgery, including resection of the stomach or gastrectomy $(n=65)$; and incomplete electronic medical records $(n=42)$. As a result, 8,356 patients were eligible and were enrolled in this study.

The study protocol conformed to the ethical guidelines of the World Medical Association Declaration of Helsinki and was approved by the Gangnam Severance Hospital Institutional Review Board (IRB No. 3-2018-0349). Informed consent was not required because this study was a retrospective analysis of existing administrative and clinical data.

\section{Anthropometric Measurements}

Anthropometric parameters of all enrolled patients were measured. Body weight and height were measured to the nearest $0.1 \mathrm{~kg}$ and $0.1 \mathrm{~cm}$, respectively, with the patients wearing lightweight clothing without shoes. To measure skeletal muscle mass, we used multi-frequency bioelectrical impedance analysis (ACCUNIQ BC 720; SELVAS healthcare, Korea), which is considered an appropriate alternative to DXA (14). Appendicular skeletal muscle mass (ASM) was calculated as the sum of appendicular lean mass from both the arms and legs (15). BMI was calculated as body weight divided by height squared $\left(\mathrm{kg} / \mathrm{m}^{2}\right)$.

We used the definition of sarcopenia developed by Janssen et al. (16); they adopted SMI to establish the prevalence of sarcopenia and defined sarcopenia as an SMI $<1$ standard deviation below the sex-specific mean for healthy adults aged 20-39 years. SMI was calculated as ASM/body weight $\times$ $100(\%)$. In our study, the cutoff value for sarcopenia was $29.3 \%$ for males and $26.7 \%$ for females. We defined obesity as BMI $\geq 25 \mathrm{~kg} / \mathrm{m}^{2}$ according to the Asia-Pacific criteria (17). Sarcopenic obesity was defined as the coexistence of sarcopenia and obesity.

\section{Questionnaire}

All patients who visited our checkup center were required to complete a questionnaire. The questionnaire included questions on combined DM, hypertension, dyslipidemia, smoking history, alcohol consumption, and diet (consumption of salty and spicy foods). Regarding diet, patients were asked to select "yes" if they consumed salty and spicy foods six times within 7 days.

\section{Endoscopic Evaluation of the Stomach}

All enrolled patients underwent endoscopic examinations using an endoscope (GIF-H260; Olympus Medical Systems, 
Tokyo, Japan) equipped with an electronic endoscopy system (EVIS LUCERA; Olympus Medical Systems). H. pylori infection was detected using the following methods: rapid urease test (CLO test; Delta West, Bentley, Australia), pathology (Giemsa staining), and immunoglobulin $G$ specific for $H$. pylori in the serum (enzyme-linked fluorescence assay, Vidas [bioMerieux Vitek, Inc. Hazelwood, MO, USA]). If the result of at least one of these three tests was positive, the patient was diagnosed with $H$. pylori infection. Gastric cancer and gastric dysplasia were confirmed by histologic examination of the tissue obtained during endoscopic biopsy. AG and IM were diagnosed based on the gross endoscopic findings reported by endoscopists with at least 3 years of experience.

\section{Statistical Analysis}

Continuous variables were reported as mean \pm standard deviation and were compared between groups using the $t$-test or Wilcoxon rank-sum test. Categorical variables were reported as numbers and percentages, and the chi-square test or Fisher's exact test was used to compare categorical variables.

Pearson's correlation analysis was used to evaluate the correlation between two continuous variables. We performed multivariate Cox regression analysis to identify the risk factors affecting gastric cancer and precancerous conditions. We performed two multivariate analyses because sarcopenic obesity is a combination of sarcopenia and obesity. Statistical analysis was performed using SPSS version 23.0 (IBM Corp., Armonk, NY, USA). A two-tailed $P$-value of $<0.05$ was considered significant.

\section{RESULTS}

\section{Baseline Characteristics}

Table 1 shows the baseline characteristics of the study population. Of 8,356 patients, 4,670 (55.9\%) were men, and the mean age was $49.1 \pm 11.6$ years. The average BMI was $23.9 \pm 3.3 \mathrm{~kg} / \mathrm{m}^{2}$. The mean SMI was $32.2 \pm 2.7 \%$ in men and $28.7 \pm 3.0 \%$ in women. Approximately $15.2 \%$ of patients were diagnosed with sarcopenia and $13.5 \%$ were diagnosed with sarcopenic obesity. Male subjects had a higher prevalence of sarcopenia (18.8\% male vs. $10.6 \%$ female) and sarcopenic obesity ( $17.3 \%$ men vs. $8.7 \%$ women). Approximately $11.2 \%$ of patients had DM, $14.3 \%$ had dyslipidemia, and $18.7 \%$ had hypertension. Overall, 12 patients had gastric cancer. Moreover, 3,622 patients were diagnosed with gastric precancerous conditions. Among these patients, 2,205 had AG, 1,407 had IM, and 10 had gastric dysplasia.

\section{Risk Factors for Gastric Cancer}

Tables 2, 3 show the risk factors for gastric cancer. In the univariate analysis, advanced age, obesity, sarcopenia, sarcopenic obesity, and DM were significantly associated with an increased risk of gastric cancer (Table 2). In the multivariate analyses, sarcopenic obesity (odds ratio $[\mathrm{OR}]=4.139,95 \%$ confidence interval $[\mathrm{CI}]: 1.304-13.133, P=0.016)$ and $\mathrm{DM}(\mathrm{OR}=5.152$,
TABLE 1 | Baseline characteristics of the study population.

\begin{tabular}{|c|c|}
\hline Characteristics & All patients $(N=8,356)$ \\
\hline Age (years, mean \pm SD) & $49.1 \pm 11.6$ \\
\hline Male (n, \%) & 4,670 (55.9) \\
\hline Height (cm, mean \pm SD) & $166.5 \pm 8.5$ \\
\hline Weight (kg, mean \pm SD) & $66.5 \pm 12.8$ \\
\hline $\mathrm{BMI}\left(\mathrm{kg} / \mathrm{m}^{2}\right.$, mean $\left.\pm \mathrm{SD}\right)$ & $23.9 \pm 3.3$ \\
\hline Obesity (n, \%) & 2,839 (34.0) \\
\hline \multicolumn{2}{|l|}{$\mathrm{SMI}(\%$, mean $\pm \mathrm{SD})$} \\
\hline Male & $32.2 \pm 2.7$ \\
\hline Female & $28.7 \pm 3.0$ \\
\hline Current smoker ( $n, \%)$ & $1,479(17.1)$ \\
\hline Alcohol history (n, \%) & $5,593(66.9)$ \\
\hline $\mathrm{DM}(n, \%)$ & $940(11.2)$ \\
\hline Dyslipidemia (n, \%) & $1,192(14.3)$ \\
\hline Hypertension (n, \%) & $1,563(18.7)$ \\
\hline Sarcopenia (n, \%) & $1,270(15.2)$ \\
\hline Male & 878/4,670 (18.8) \\
\hline Female & 392/3,686 (10.6) \\
\hline Sarcopenic obesity (n, \%) & $1,129(13.5)$ \\
\hline Male & $810 / 4,670(17.3)$ \\
\hline Female & $319 / 3,686(8.7)$ \\
\hline Diet, salty and/or spicy (n, \%) & $3,398(40.7)$ \\
\hline H. pylori infection (n, \%) & $1,217(14.6)$ \\
\hline Gastric cancer (n, \%) & $12(0.14)$ \\
\hline Gastric precancerous conditions ( $n, \%)$ & $3,622(43.3)$ \\
\hline Atrophic gastritis ( $n, \%)$ & $2,205(26.4)$ \\
\hline Intestinal metaplasia ( $n, \%)$ & 1,407 (16.8) \\
\hline Dysplasia (n, \%) & $10(0.12)$ \\
\hline
\end{tabular}

BMI, body mass index; SMI, skeletal muscle index; DM, diabetes mellitus; H. pylori, Helicobacter pylori.

95\% CI: $1.624-16.347, P=0.005)$ were significant risk factors for gastric cancer (Table 3 ).

\section{Risk Factors for Gastric Precancerous Conditions}

Tables 4, 5 show the risk factors for gastric precancerous conditions. In the univariate analysis, advanced age, obesity, smoking, alcohol consumption, sarcopenia, sarcopenic obesity, H. pylori infection, DM, dyslipidemia, hypertension, and diet, which included consumption of salty and/or spicy foods, were significantly associated with gastric precancerous conditions (Table 4). Among these factors, sarcopenia (OR $=1.201,95 \%$ CI: $1.039-1.387, P=0.013$ ) was independently associated with gastric precancerous conditions. Moreover, smoking $(\mathrm{OR}=$ 1.195, 95\% CI: 1.081-1.320, $P=0.001$ ), alcohol consumption $(\mathrm{OR}=1.316,95 \% \mathrm{CI}: 1.189-1.456, P<0.001), \mathrm{DM}(\mathrm{OR}=1.533$, 95\% CI: $1.320-1.782, P<0.001)$, hypertension $(\mathrm{OR}=1.412,95 \%$ CI: 1.244-1.603, $P<0.001$ ), dyslipidemia (OR $=1.552$, 95\% CI: $1.357-1.775, P<0.001)$, and $H$. pylori infection $(\mathrm{OR}=3.954$, 95\% CI: 3.454-4.057, $P<0.001)$ were independent risk factors for gastric precancerous conditions (Table 5). 
TABLE 2 | Univariate analysis of the risk factors for gastric cancer.

\begin{tabular}{lccc}
\hline & \multicolumn{3}{c}{ Univariate analysis } \\
\cline { 2 - 4 } & $\begin{array}{c}\text { Control } \\
(\boldsymbol{n}=\mathbf{8 , 3 4 4 )}\end{array}$ & $\begin{array}{c}\text { Cancer } \\
(\boldsymbol{n}=\mathbf{1 2})\end{array}$ & $\boldsymbol{P}$-value \\
\hline Age (years, mean \pm SD) & $49.0 \pm 11.6$ & $58.8 \pm 13.8$ & 0.003 \\
Male $(n, \%)$ & $4,633(55.9)$ & $7(58.3)$ & 0.864 \\
Obesity $(n, \%)$ & $2,831(33.9)$ & $8(66.7)$ & 0.028 \\
Current smoker $(n, \%)$ & $1,477(17.7)$ & $2(16.7)$ & 1.000 \\
Alcohol history $(n, \%)$ & $5,588(67.0)$ & $5(41.7)$ & $<0.001$ \\
DM (n, \%) & $935(11.2)$ & $5(41.7)$ & 0.007 \\
Dyslipidemia $(n, \%)$ & $1,190(14.3)$ & $2(16.7)$ & 0.685 \\
Hypertension $(n, \%)$ & $1,158(18.7)$ & $5(41.7)$ & 0.056 \\
Diet, salty and/or spicy $(n, \%)$ & $3,391(40.6)$ & $7(58.3)$ & 0.247 \\
H. pylori infection $(n, \%)$ & $1,213(14.5)$ & $4(33.3)$ & 0.084 \\
Sarcopenia $(n, \%)$ & $1,265(15.2)$ & $5(41.7)$ & 0.025 \\
Sarcopenic obesity $(n, \%)$ & $1,124(13.5)$ & $5(41.7)$ & 0.016 \\
\hline
\end{tabular}

DM, diabetes mellitus; H. pylori, Helicobacter pylori.

TABLE 3 | Multivariate analyses of the risk factors for gastric cancer.

\begin{tabular}{|c|c|c|c|c|}
\hline & \multicolumn{2}{|c|}{ Multivariate analysis 1} & \multicolumn{2}{|c|}{ Multivariate analysis 2} \\
\hline & OR (95\% Cl) & $P$-value & OR (95\% Cl) & $P$-value \\
\hline $\mathrm{DM}$ & $\begin{array}{c}5.000 \\
(1.575-15.870)\end{array}$ & 0.006 & $\begin{array}{c}5.152 \\
(1.624-16.347)\end{array}$ & 0.005 \\
\hline Sarcopenia & $\begin{array}{c}2.122 \\
(0.557-8.086)\end{array}$ & 0.270 & - & - \\
\hline Obesity & $\begin{array}{c}2.522 \\
(0.623-10.203)\end{array}$ & 0.195 & - & - \\
\hline $\begin{array}{l}\text { Sarcopenic } \\
\text { obesity }\end{array}$ & - & - & $\begin{array}{c}4.139 \\
(1.304-13.133)\end{array}$ & 0.016 \\
\hline
\end{tabular}

$O R$, odds ratio; $D M$, diabetes mellitus; $\mathrm{Cl}$, confidence interval.

Multivariate analysis 1: Adjusted for DM, sarcopenia, and obesity. Multivariate analysis 2: Adjusted for DM and sarcopenic obesity.

\section{DISCUSSION}

Our study showed that sarcopenia and sarcopenic obesity were significantly associated with gastric carcinogenesis. A possible explanation for these associations might be related to metabolic syndrome. DM, hypertension, and dyslipidemia, which are components of metabolic syndrome, are also significantly associated with gastric carcinogenesis in our study.

As reported in previous studies, DM is considered a risk factor for gastric cancer (18-21). There are several suggested mechanisms to explain the pathogenic role of DM in gastric carcinogenesis. Patients with hyperglycemia may develop insulin resistance, and an increase in insulin levels may induce cell proliferation. This process may cause changes in the gastric mucosa and genetic alterations, eventually leading to gastric carcinogenesis (22). Increases in reactive oxygen species caused by DM and high glucose levels are associated with mutational changes in oncogenes
TABLE 4 | Univariate analysis of the risk factors for gastric precancerous conditions.

\begin{tabular}{lccc}
\hline & \multicolumn{3}{c}{ Univariate analysis } \\
\cline { 2 - 4 } & $\begin{array}{c}\text { Control } \\
(\boldsymbol{n}=\mathbf{4 , 7 2 2})\end{array}$ & $\begin{array}{c}\text { Precancerous } \\
\text { conditions } \\
(\boldsymbol{n}=\mathbf{3 , 6 2 2})\end{array}$ & $\boldsymbol{P}$-value \\
\hline Age (years, mean \pm SD) & $46.0 \pm 11.0$ & $53.2 \pm 11.0$ & $<0.001$ \\
Male (n, \%) & $2,663(55.2)$ & $2,000(56.8)$ & 0.156 \\
Obesity $(n, \%)$ & $1,591(33.0)$ & $1,240(35.2)$ & 0.035 \\
Current smoker (n, \%) & $1,848(38.3)$ & $1,475(41.9)$ & 0.001 \\
Alcohol history (n, \%) & $1,487(30.8)$ & $1,269(36.0)$ & $<0.001$ \\
DM (n, \%) & $407(8.4)$ & $528(15.0)$ & $<0.001$ \\
Dyslipidemia (n, \%) & $556(11.5)$ & $634(18.0)$ & $<0.001$ \\
Hypertension ( $n, \%)$ & $737(15.3)$ & $821(23.3)$ & $<0.001$ \\
Diet, salty and/or spicy $(n, \%)$ & $1,903(39.5)$ & $1,488(42.2)$ & 0.011 \\
H. pylori infection $(n, \%)$ & $375(7.8)$ & $838(23.8)$ & $<0.001$ \\
Sarcopenia $(n, \%)$ & $671(13.9)$ & $594(16.9)$ & $<0.001$ \\
Sarcopenic obesity $(n, \%)$ & $610(12.7)$ & $514(14.6)$ & 0.010 \\
\hline
\end{tabular}

DM, diabetes mellitus; H. pylori, Helicobacter pylori.

TABLE 5 | Multivariate analyses of the risk factors for gastric precancerous conditions.

\begin{tabular}{|c|c|c|c|c|}
\hline & \multicolumn{2}{|c|}{ Multivariate analysis 1} & \multicolumn{2}{|c|}{ Multivariate analysis 2} \\
\hline & OR (95\% Cl) & $P$-value & OR (95\% Cl) & $P$-value \\
\hline $\begin{array}{l}\text { Current } \\
\text { smoker }\end{array}$ & $\begin{array}{c}1.195 \\
(1.081-1.320)\end{array}$ & 0.001 & $\begin{array}{c}1.186 \\
(1.075-1.308)\end{array}$ & 0.001 \\
\hline Alcohol & $\begin{array}{c}1.316 \\
(1.189-1.456)\end{array}$ & $<0.001$ & $\begin{array}{c}1.322 \\
(1.195-1.463)\end{array}$ & $<0.001$ \\
\hline DM & $\begin{array}{c}1.533 \\
(1.320-1.782)\end{array}$ & $<0.001$ & $\begin{array}{c}1.536 \\
(1.322-1.748)\end{array}$ & $<0.001$ \\
\hline Hypertension & $\begin{array}{c}1.412 \\
(1.244-1.603)\end{array}$ & $<0.001$ & $\begin{array}{c}1.411 \\
(1.243-1.601)\end{array}$ & $<0.001$ \\
\hline Dyslipidemia & $\begin{array}{c}1.552 \\
(1.357-1.775)\end{array}$ & $<0.001$ & $\begin{array}{c}1.554 \\
(1.359-1.777)\end{array}$ & $<0.001$ \\
\hline $\begin{array}{l}\text { H. pylori } \\
\text { infection }\end{array}$ & $\begin{array}{c}3.954 \\
(3.454-4.507)\end{array}$ & $<0.001$ & $\begin{array}{c}3.938 \\
(3.448-4.498)\end{array}$ & $<0.001$ \\
\hline $\begin{array}{l}\text { Diet, salty } \\
\text { and/or spicy }\end{array}$ & $\begin{array}{c}1.100 \\
(1.003-1.206)\end{array}$ & 0.054 & $\begin{array}{c}1.099 \\
(1.003-1.206)\end{array}$ & 0.054 \\
\hline Sarcopenia & $\begin{array}{c}1.201 \\
(1.039-1.387)\end{array}$ & 0.013 & - & - \\
\hline Obesity & $\begin{array}{c}1.934 \\
(0.834-1.045)\end{array}$ & 0.233 & - & - \\
\hline $\begin{array}{l}\text { Sarcopenic } \\
\text { obesity }\end{array}$ & - & - & $\begin{array}{c}1.075 \\
(0.942-1.228)\end{array}$ & 0.284 \\
\hline
\end{tabular}

OR, odds ratio; DM, diabetes mellitus; $H$. pylori, Helicobacter pylori; $\mathrm{Cl}$, confidence interval.

Multivariate analysis 1: Adjusted for smoking, alcohol, DM, hypertension, dyslipidemia, $\mathrm{H}$. pylori infection, diet, sarcopenia, and obesity. Multivariate analysis 2: Adjusted for smoking, alcohol, DM, hypertension, dyslipidemia, H. pylori infection, diet, and sarcopenic obesity.

and tumor suppressor genes. This change contributes to gastric carcinogenesis $(23,24)$. The increase in insulinlike growth factors in DM patients plays an important role in the initiation, progression, and metastasis of gastric cancer (25). 
In our study, $H$. pylori infection is significantly associated with precancerous conditions. H. pylori infection is a wellknown risk factor for gastric carcinogenesis as reported in previous studies. Moreover, one prospective study reported that $\mathrm{DM}$ and $H$. pylori infection have synergistic effects on gastric carcinogenesis (26). DM may increase the risk of gastric carcinogenesis by stimulating epithelial cell proliferation, which is the initial step in the cascade of gastric carcinogenesis, because of the presence of $H$. pylori. H. pylori infection stimulates pancreatic insulin release by increasing gastrin secretion and decreasing the serum somatostatin level $(27,28)$. One clinical study reported that patients with $H$. pylori infection have higher insulin resistance (29).

Meanwhile, the association between hypertension and gastric cancer is unclear. However, a previous study explained that gastric cancer and hypertension have a common biochemical pathway. Increased levels of inositol triphosphate and cytosolic calcium are involved in the pathogenesis of hypertension and carcinogenesis stage (30).

Previous studies reported the association between obesity and gastric carcinogenesis. A clinical study showed that the effect of obesity on gastric cancer may differ depending on sex (31). In males, obesity was associated with an increased risk of early gastric cancer and well or moderately differentiated adenocarcinoma. In females, obesity was associated with gastric dysplasia regardless of $H$. pylori infection. One meta-analysis conducted in a cohort and case-control study reported that obesity was associated with the risk of gastric cancer in male and non-Asian patients (32). This study showed that both overweight and obesity were associated with the risk of gastric cardia cancer. In our study, obesity was not significantly associated with an increased risk of gastric carcinogenesis. This finding may be due to the fact that stratified analysis was not performed according to sex and the location of the cancer. However, sarcopenic obesity, combined with sarcopenia and obesity, is a risk factor for gastric cancer. Recent studies have shown that sarcopenic obesity affects the development of cardiometabolic diseases (3337). These studies also reported that sarcopenic obesity has a strong relationship with metabolic syndrome and is associated with a higher risk of metabolic disorders and mortality than obesity or sarcopenia alone.

In 1998, Baumgartner et al. first defined sarcopenia as ASM $/$ height $^{2}\left(\mathrm{~kg} / \mathrm{m}^{2}\right)<2$ standard deviations below the mean of a young reference group (38). Although several different definitions of sarcopenia have since been suggested $(38,39)$, a widely accepted definition suitable for use in research and clinical practice is still pending because of a lack of consensus $(8,13)$. Similar to gastric carcinogenesis, agerelated sarcopenia is also associated with the development of metabolic syndrome. The expression of glucose transporter type 4, which facilitates the uptake of glucose, is related to the volume of skeletal muscle fiber (40). Therefore, sarcopenia can cause insulin intolerance that leads to metabolic syndrome. Sarcopenia and metabolic syndrome develop a vicious cycle (41). The loss of muscle mass because of sarcopenia results in decreased physical activity, causing visceral fat to accumulate in the body. Because skeletal muscle is an insulinresponse target tissue, sarcopenia patients develop progressive metabolic syndrome.

Adipose tissue secretes proinflammatory cytokines such as tumor necrosis factor $\alpha$ and interleukin-6, thereby regulating carbohydrate and fat metabolism. These cytokines are also associated with protein degradation; thus, sarcopenia can be accelerated in individuals with long-standing obesity. Therefore, especially in the elderly population, obesity and sarcopenia should also be considered as sarcopenic obesity (42).

Our study has several strengths over previous studies. First, our data were collected from a health checkup cohort. Most health checkup centers routinely obtain patients' anthropometric measurements, including weight, height, and skeletal muscle mass. Not only obesity but also sarcopenia and sarcopenic obesity can be diagnosed through this routine measurement. However, most physicians focus on obesity. Based on our study, this routine measurement may be a useful tool for predicting gastric carcinogenesis. Second, our study analyzed risk factors for gastric carcinogenesis, including gastric cancer and precancerous conditions. Gastric cancer is one of the heterogeneous cancers that involves a multistep process from precancerous conditions to cancer. Therefore, the result of our study indicates the importance of controlling the risk factors of gastric carcinogenesis.

Our study also had several limitations. First, because our data were obtained from an asymptomatic and healthy checkup cohort, only a few patients diagnosed with gastric cancer who underwent screening endoscopy were enrolled in this study. Therefore, a large-scale study is warranted to confirm our results. Second, patient information, such as medical history, alcohol consumption, smoking, and diet, was collected using a questionnaire. However, the questionnaire did not include the exact amount of alcohol consumption, frequency of smoking, and amount and concentration of food components consumed. Third, although current definitions, such as those of the European Working Group on Sarcopenia in Older People, the European Society for Clinical Nutrition and Metabolism Special Interest Groups, and the International Working Group on Sarcopenia, define sarcopenia as muscle mass and function $(8,43-45)$, our study adopted only muscle mass. This was because our checkup center did not have a device to measure muscle function. Most checkup centers' routine programs only include muscle mass. Therefore, the result of our study may be sufficient to predict gastric carcinogenesis in healthy subjects. Fourth, precancerous conditions, including AG and IM, were diagnosed only based on gross endoscopic findings rather than on biopsy. However, the diagnosis of precancerous conditions was considered reliable as the endoscopists had sufficient experience (at least 3 years) in diagnosing these types of conditions.

In conclusion, sarcopenia and sarcopenic obesity may be novel risk factors for gastric carcinogenesis. Hence, controlling SMI and BMI as estimators of sarcopenia and sarcopenic obesity may be important for preventing gastric cancer. Our study only identified the association between sarcopenia and sarcopenic obesity and gastric carcinogenesis to prove our hypothesis. 
Therefore, further research should be performed to clarify the precise mechanism of this association.

\section{DATA AVAILABILITY STATEMENT}

The datasets generated for this study are available on reasonable request to the corresponding author.

\section{ETHICS STATEMENT}

The studies involving human participants were reviewed and approved by Institutional Review Board of Gangnam Severance Hospital (IRB no. 3-2018-0349). Written informed consent for participation was not required for this study in accordance with the national legislation and the institutional requirements.

\section{AUTHOR CONTRIBUTIONS}

YK: substantial contributions to conception and design, analysis and interpretation of data, drafting the article, and revising it critically for important intellectual content. J-HK:

\section{REFERENCES}

1. Torre LA, Bray F, Siegel RL, Ferlay J, Lortet-Tieulent J, Jemal A. Global Cancer Statistics, 2012. Ca Cancer J Clin. (2015) 65:87-108. doi: 10.3322/caac.21262

2. Lee S, Jun JK, Suh M, Park B, Noh DK, Jung KW, et al. Gastric cancer screening uptake trends in Korea: results for the national cancer screening program from 2002 to 2011 a prospective cross-sectional study. Medicine. (2015) 94:e13247. doi: 10.1097/MD.0000000000000533

3. Correa P, Piazuelo MB. The gastric precancerous cascade. J Dig Dis. (2012) 13:2-9. doi: 10.1111/j.1751-2980.2011.00550.x

4. Correa P. Human gastric carcinogenesis: a multistep and multifactorial process-First American Cancer Society Award Lecture on Cancer Epidemiology and Prevention. Cancer Res. (1992) 52:6735-40.

5. Tan P, Yeoh KG. Genetics and molecular pathogenesis of gastric adenocarcinoma. Gastroenterology. (2015) 149:1153-62.e3. doi: 10.1053/j.gastro.2015.05.059

6. Bouvard V, Loomis D, Guyton KZ, Grosse Y, Ghissassi FE, Benbrahim-Tallaa L, et al. Carcinogenicity of consumption of red and processed meat. Lancet Oncol. (2015) 16:1599-600. doi: 10.1016/S1470-2045(15)00444-1

7. Braun S, Bitton-Worms K, LeRoith D. The link between the metabolic syndrome and cancer. Int J Biol Sci. (2011) 7:1003-15. doi: 10.7150/ijbs.7.1003

8. Cruz-Jentoft AJ, Baeyens JP, Bauer JM, Boirie Y, Cederholm T, Landi F, et al. Sarcopenia: European consensus on definition and diagnosis: report of the European Working Group on Sarcopenia in Older People. Age Ageing. (2010) 39:412-23. doi: 10.1093/ageing/afq034

9. Shafiee G, Keshtkar A, Soltani A, Ahadi Z, Larijani B, Heshmat R. Prevalence of sarcopenia in the world: a systematic review and metaanalysis of general population studies. J Diabetes Metab Disord. (2017) 16:21. doi: 10.1186/s40200-017-0302-x

10. Pongchaiyakul C, Limpawattana P, Kotruchin P, Rajatanavin R. Prevalence of sarcopenia and associated factors among Thai population. J Bone Miner Metab. (2013) 31:346-50. doi: 10.1007/s00774-013-0422-4

11. Klip A, Paquet MR. Glucose-transport and glucose transporters in muscle and their metabolic-regulation. Diabetes Care. (1990) 13:228-43. doi: $10.2337 /$ diacare.13.3.228

12. Cleasby ME, Jamieson PM, Atherton PJ. Insulin resistance and sarcopenia: mechanistic links between common co-morbidities. J Endocrinol. (2016) 229:R67-81. doi: 10.1530/JOE-15-0533 substantial contributions to conception and design, final approval of the version to be published, and agreement to be accountable for all aspects of the work. SB: acquisition of data. JC, YY, and HP: revising the article critically for important intellectual content. All authors: review the manuscript.

\section{FUNDING}

The Basic Science Research Program through the National Research Foundation of Korea funded by the Ministry of Education, Science and Technology (2018R1A2B6008139).

\section{ACKNOWLEDGMENTS}

The authors would like to acknowledge that this work was presented at KDDW 2018 conference on November 15th, 2018 in Seoul, the 16th Japan-Korea Joint Symposium on Helicobacter Research conference on March 9th, 2019 in Busan, KINGCA WEEK 2019 conference on April 13th, 2019 in Incheon, and DDW 2019 conference on May 19th, 2019 in San Diego.

13. Wannamethee SG, Atkins JL. Muscle loss and obesity: the health implications of sarcopenia and sarcopenic obesity. Proc Nutr Soc. (2015) 74:405-12. doi: 10.1017/S002966511500169X

14. Anderson LJ, Erceg DN, Schroeder ET. Utility of multifrequency bioelectrical impedance compared with dual-energy x-ray absorptiometry for assessment of total and regional body composition varies between men and women. Nutr Res. (2012) 32:479-85. doi: 10.1016/j.nutres.2012.05.009

15. Delmonico MJ, Harris TB, Lee JS, Visser M, Nevitt M, Kritchevsky SB, et al. Alternative definitions of sarcopenia, lower extremity performance, and functional impairment with aging in older men and women. J Am Geriatr Soc. (2007) 55:769-74. doi: 10.1111/j.1532-5415.2007.01140.x

16. Janssen I, Heymsfield SB, Ross R. Low relative skeletal muscle mass (sarcopenia) in older persons is associated with functional impairment and physical disability. J Am Geriatr Soc. (2002) 50:889-96. doi: 10.1046/j.1532-5415.2002.50216.x

17. Pan WH, Yeh WT. How to define obesity? Evidence-based multiple action points for public awareness, screening, and treatment: an extension of AsianPacific recommendations. Asia Pac J Clin Nutr. (2008) 17:370-4.

18. Lin YL, Ness-Jensen E, Hveem K, Lagergren J, Lu YX. Metabolic syndrome and esophageal and gastric cancer. Cancer Cause Control. (2015) 26:1825-34. doi: 10.1007/s10552-015-0675-4

19. Miao ZF, Xu H, Xu YY, Wang ZN, Zhao TT, Song YX, et al. Diabetes mellitus and the risk of gastric cancer: a meta-analysis of cohort studies. Oncotarget. (2017) 8:44881-92. doi: 10.18632/oncotarget.16487

20. Jee SH, Ohrr H, Sull JW, Yun JE, Min J, Samet JM. Fasting serum glucose level and cancer risk in Korean men and women - Reply. Jama-J Am Med Assoc. (2005) 293:194-202. doi: 10.1001/jama.293.2.194

21. Lin SW, Freedman ND, Hollenbeck AR, Schatzkin A, Abnet CC. Prospective study of self-reported diabetes and risk of upper gastrointestinal cancers. Cancer Epidem Biomar. (2011) 20:954-61. doi: 10.1158/1055-9965.EPI-10-1244

22. Ogihara S, Yamada M, Saito T, Shono M, Rokutan K. Insulin potentiates mitogenic effect of epidermal growth factor on cultured guinea pig gastric mucous cells. Am J Physiol. (1996) 271(1 Pt 1):G104-12. doi: 10.1152/ajpgi.1996.271.1.G104

23. Dandona P, Thusu K, Cook S, Snyder B, Makowski J, Armstrong D, et al. Oxidative damage to DNA in diabetes mellitus. Lancet. (1996) 347:444-5. doi: 10.1016/S0140-6736(96)90013-6 
24. Lorenzi M, Montisano DF, Toledo S, Barrieux A. High glucose induces DNA damage in cultured human endothelial cells. J Clin Invest. (1986) 77:322-5. doi: 10.1172/JCI112295

25. Yi HK, Hwang PH, Yang DH, Kang CW, Lee DY. Expression of the insulin-like growth factors (IGFs) and the IGF-binding proteins (IGFBPs) in human gastric cancer cells. Eur J Cancer. (2001) 37:2257-63. doi: 10.1016/S0959-8049(01)00269-6

26. Ikeda F, Doi Y, Yonemoto K, Ninomiya T, Kubo M, Shikata K, et al. Hyperglycemia increases risk of gastric cancer posed by Helicobacter pylori infection: a population-based cohort study. Gastroenterology. (2009) 136:1234-41. doi: 10.1053/j.gastro.2008.12.045

27. Acbay O, Celik AF, Gundogdu S. Does Helicobacter pylori-induced gastritis enhance food-stimulated insulin release? Digest Dis Sci. (1996) 41:1327-31. doi: 10.1007/BF02088555

28. Kaneko H, Konagaya T, Kusugami K. Helicobacter pylori and gut hormones. J Gastroenterol. (2002) 37:77-86. doi: 10.1007/s005350200000

29. Aydemir S, Bayraktaroglu T, Sert M, Sokmen C, Atmaca H, Mungan G, et al. The effect of Helicobacter pylori on insulin resistance. Dig Dis Sci. (2005) 50:2090-3. doi: 10.1007/s10620-005-3012-z

30. Li FX, Du H, Li SX, Liu JT. The Association Between metabolic syndrome and gastric cancer in Chinese. Front Oncol. (2018) 8:326. doi: $10.3389 /$ fonc. 2018.00326

31. Kim HJ, Kim N, Kim HY, Lee HS, Yoon H, Shin CM, et al. Relationship between body mass index and the risk of early gastric cancer and dysplasia regardless of Helicobacter pylori infection. Gastric Cancer. (2015) 18:762-73. doi: 10.1007/s10120-014-0429-0

32. Lin XJ, Wang CP, Liu XD, Yan KK, Li S, Bao HH, et al. Body mass index and risk of gastric cancer: a meta-analysis. Jpn J Clin Oncol. (2014) 44:783-91. doi: $10.1093 /$ jjco/hyu082

33. Baumgartner RN. Body composition in healthy aging. Ann N Y Acad Sci. (2000) 904:437-48. doi: 10.1111/j.1749-6632.2000.tb06498.x

34. Kohara K. Sarcopenic obesity in aging population: current status and future directions for research. Endocrine. (2014) 45:15-25. doi: 10.1007/s12020-013-9992-0

35. Stenholm S, Harris TB, Rantanen T, Visser M, Kritchevsky SB, Ferrucci L. Sarcopenic obesity: definition, cause and consequences. Curr Opin Clin Nutr Metab Care. (2008) 11:693-700. doi: 10.1097/MCO.0b013e328312c37d

36. Lu CW, Yang KC, Chang HH, Lee LT, Chen CY, Huang KC. Sarcopenic obesity is closely associated with metabolic syndrome. Obes Res Clin Pract. (2013) 7:E301-7. doi: 10.1016/j.orcp.2012.02.003

37. Zamboni M, Mazzali G, Fantin F, Rossi A, Di Francesco V. Sarcopenic obesity: a new category of obesity in the elderly. Nutr Metab Cardiovasc Dis. (2008) 18:388-95. doi: 10.1016/j.numecd.2007.10.002
38. Baumgartner RN, Koehler KM, Gallagher D, Romero L, Heymsfield SB, Ross RR, et al. Epidemiology of sarcopenia among the elderly in New Mexico. Am J Epidemiol. (1998) 147:755-63. doi: 10.1093/oxfordjournals.aje. a009520

39. Newman AB, Haggerty CL, Goodpaster B, Harris T, Kritchevsky S, Nevitt M, et al. Strength and muscle quality in a well-functioning cohort of older adults: the Health, Aging and Body Composition Study. J Am Geriatr Soc. (2003) 51:323-30. doi: 10.1046/j.1532-5415.2003.51105.x

40. Gaster M, Vach W, Beck-Nielsen H, Schroder HD. GLUT4 expression at the plasma membrane is related to fibre volume in human skeletal muscle fibres. Apmis. (2002) 110:611-9. doi: 10.1034/j.1600-0463.2002. 1100903.x

41. Choi KM. Sarcopenia and sarcopenic obesity. Endocrinol Metab. (2013) 28:86-9. doi: 10.3803/EnM.2013.28.2.86

42. Baumgartner RN, Wayne SJ, Waters DL, Janssen I, Gallagher D, Morley JE. Sarcopenic obesity predicts instrumental activities of daily living disability in the elderly. Obes Res. (2004) 12:1995-2004. doi: 10.1038/oby. 2004.250

43. Cruz-Jentoft AJ, Bahat G, Bauer J, Boirie Y, Bruyere O, Cederholm T, et al. Sarcopenia: revised European consensus on definition and diagnosis. Age and Ageing. (2019) 48:16-31. doi: 10.1093/ageing/afy169

44. Muscaritoli M, Anker SD, Argiles J, Aversa Z, Bauer JM, Biolo G, et al. Consensus definition of sarcopenia, cachexia and pre-cachexia: joint document elaborated by Special Interest Groups (SIG) "cachexia-anorexia in chronic wasting diseases" and "nutrition in geriatrics". Clin Nutr. (2010) 29:154-9. doi: 10.1016/j.clnu.2009.12.004

45. Fielding RA, Vellas B, Evans WJ, Bhasin S, Morley JE, Newman AB, et al. Sarcopenia: an undiagnosed condition in older adults. Current consensus definition: prevalence, etiology, and consequences. International working group on sarcopenia. J Am Med Dir Assoc. (2011) 12:249-56. doi: 10.1016/j.jamda.2011.01.003

Conflict of Interest: The authors declare that the research was conducted in the absence of any commercial or financial relationships that could be construed as a potential conflict of interest.

Copyright (c) $2019 \mathrm{Kim}$, Kim, Baik, Chun, Youn and Park. This is an open-access article distributed under the terms of the Creative Commons Attribution License (CC $B Y)$. The use, distribution or reproduction in other forums is permitted, provided the original author(s) and the copyright owner(s) are credited and that the original publication in this journal is cited, in accordance with accepted academic practice. No use, distribution or reproduction is permitted which does not comply with these terms. 